UDC 615.12 : 339.137

DOI: 10.15587/2519-4852.2021.230287

\title{
PECULIARITIES OF EFFECTIVE MANAGEMENT OF PRODUCTS ASSORTMENT DEPENDING ON DIFFERENT SIZES OF PHARMACY CHAINS
}

\author{
Olga Posilkina, Iryna Bondarieva, Volodymyr Malyi, Iryna Timanyuk, Zhanna Mala
}

\begin{abstract}
The aim of the work is to study the features of effective management of product's assortment in small, medium and large pharmacy chains.

Materials and methods. The study of the features of the assortment policy of pharmacies that are part of pharmacy chains of different sizes was conducted using a questionnaire of 421 heads of pharmacies. The relationship between the size of the pharmacy chain and the approaches used to form the product's assortment is studied and the presence of the procedure of product's assortment formation in pharmacies is analyzed using Pearson's criteria $\chi^{2}$ and $\chi^{2}$ maximum likelihood $\left(M-L \chi^{2}\right)$. The importance of the influence of the size of the pharmacy network on the scores of the efficiency of the business process of forming the product range, as well as its width and intensity of updating using nonparametric analysis of variance Kraskal-Wallis; Manfer-Whitney test with Bonferroni correction for pairwise comparisons of pharmacy network clusters and correlation analysis. The presence of drugs in treatment protocols was analyzed using the Z-test to compare the frequency of drug administration. Peculiarities of introduction and withdrawal of drugs and medical products to the range of different size pharmacy chains criteria $\chi^{2}$ Pearson's and maximum likelihood $\left(M-L \chi^{2}\right)$ are determined. System and logical analysis is used to systematize the existing approaches to product's assortment management in pharmacy chains of different sizes.
\end{abstract}

Results. It is established that with the increase in the size of pharmacy chains the tendency to use a centralized approach to the analysis and formation of the range in chains increases, when the list of assortment items is fully created and approved at the head office of the chain. The importance of the relationship between the breadth of the assortment of pharmacies and the size of the chain, which includes a pharmacy. Thus, large and mega-chains support the assortment, which on average includes up to 8.5 thousand items of medicines and medical devices, medium - 4-5 thousand assortment's items, and in half of the establishments of small pharmacy chains the range may include from 2,5 to 3 thousand names of medicines and medical devices. It is established that regardless of the size of the pharmacy chain, the inclusion of medicines / medical products in the range of pharmacies most often takes into account the factor of seasonality of demand and taking into account the core range, i.e. the list of 100-150 most popular items in the pharmaceutical market. When withdrawing medicines or medical products from the assortment of pharmacies from all three clusters are often guided by indicators of low profitability of sales and lack of orders for goods for more than three months.

Conclusions. The analysis of the assortment policy of pharmacy chains of different sizes showed that in most of the studied institutions it is quite effective. The obtained results allow us to conclude that the effectiveness of the formation and analysis of the assortment is achieved through the use of different approaches to the centralization of this business process depending on the size of the pharmacy chain

Keywords: product range, approaches to assortment formation, pharmacy chains, medicines, medical products

How to cite:

Posilkina, O., Bondarieva, I., Malyi, V., Timanyuk, I., Mala, Z. (2021). Peculiarities of effective management of products assortment depending on different sizes of pharmacy chains. ScienceRise: Pharmaceutical Science, 2 (30), 55-63. doi: http://doi.org/10.15587/2519-4852.2021.230287

(C) The Author(s) 2021

This is an open access article under the Creative Commons CC BY license

\section{Introduction}

Assortment management is one of the most important functions of any pharmacy. The efficiency of its work and the level of competitiveness largely depend on its range. At the present stage of development of the retail segment of the pharmaceutical market of Ukraine, which is characterized by a large number of pharmacy chains (PC) (over $70 \%$ of the pharmaceutical market) and single pharmacies, and each pharmacy store (PS) is forced to address effective range management. And if we take into account that more than 14,000 trade names of medicines are sold in Ukraine, it becomes obvious that this is a difficult task. It is also natural that in performing such work, many PS rely on the expert opinion of procurement specialists or to analyze the activities of their competitors.

Management of PC range according to the principles of category management is studied in the publication [1]; analysis of the corresponding influence of the size of the range on its diversity are presented in the publication [2]; the use of the economic component in the formation of the assortment policy of 
pharmacy enterprises is studied in [3]; in the publication [4] the influence of assortment placement is determined. The publication [5] explores the study of the range of drugs. Scientific approaches to the analysis and determination of prospects for market development and analysis of the range of drugs and parapharmaceuticals are presented in $[6,7]$. The publication [8] provides tools for automated integrated $\mathrm{ABC} /$ FMR / (XYZ) / VED-analysis. The paper [9] presents the results of the analysis of the dynamic formation of the range with limited inventories. The effects of multi-channel range integration on consumer choice were studied in [10]; the publication [11] identifies the benefits of purchasing through multi-channel integration of the range and moderator role of the retail type. The use of visual design to improve customer perception of the range is presented in the publication [12]. The current state and prospects of the drug market have been studied in $[13,14]$. The influence of methods of structuring problems and the movement of analytics is studied in the publication [15]. Retail range optimization is presented in the publication [16]. The model of field decision-making is presented in [17], and the three-dimensional structure is described in the publication [17]. The system of dynamic assortment is revealed in [18].

However, the issues of product range (PR) management in the $\mathrm{PC}$, depending on the number of store units (SU) in their composition based on the use of modern mathematical apparatus remain out of the attention of scientists.

The aim of the work is to study the features of effective product range management in small, medium and large PC.

\section{Research planning (methodology)}

In the course of the work, a study of the peculiarities of the assortment policy of pharmacies (PS), which are part of the $\mathrm{PC}$, with different sales volumes and number of establishments, was conducted using a survey of 421 heads of PS or mega-PC (they contain from 11 to $50 \mathrm{SU}), 191(45.4 \%)$ - are part of the medium-sized PC (they have from 6 to $10 \mathrm{SU})$, and $92(21.8 \%$ ) - to small PC (they contain from 2 to $5 \mathrm{SU}$ ) [19].

In order to improve the range management in the PC developed an algorithm for analysis and formation of PR PS, which are part of small, medium and large PC (Fig. 1).

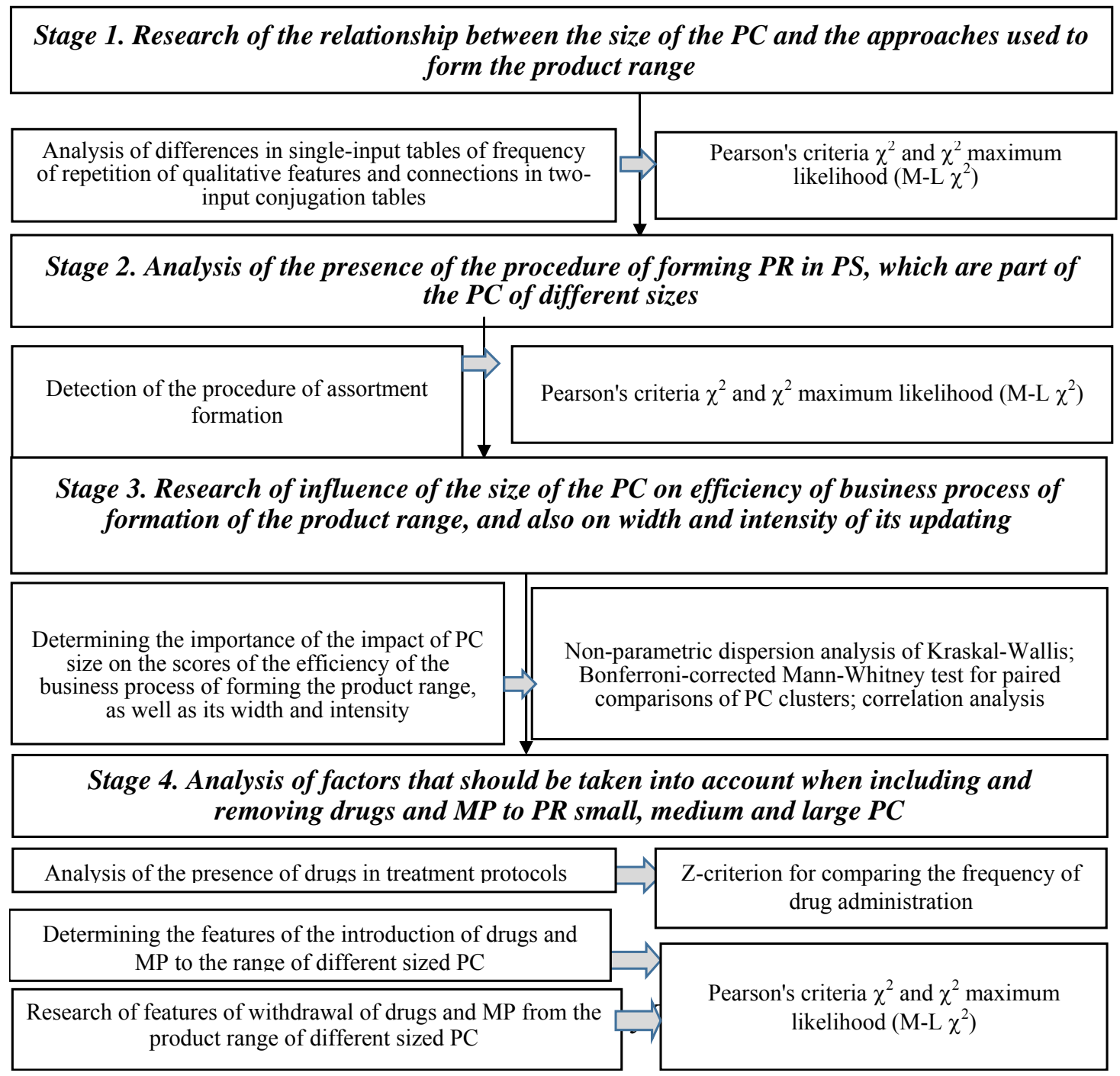

Fig. 1. Algorithm for analysis and formation of PR PS, which are part of small, medium and large PCs 
In order to identify the features and factors of assortment policy that are significantly related to the size of the PC, the criteria $\chi^{2}$ Pearson and $\chi^{2}$ maximum likelihood (M-L $\chi^{2}$ ) were used to analyze differences in single-input tables of frequencies of qualitative features and relationships in two-input tables conjugation [20].

\section{Materials and methods}

The work uses systematic and logical analysis, questionnaires, methods of economic and statistical analysis.

A survey was conducted according to our questionnaire, which included 37 questions to study the opinion of PC managers and employees on the effective management of PR in different PCs. The number of respondents was 421 , i.e. it is sufficient to obtain a marginal sampling error of no more than $5.0 \%$ [20].

The reliability of the results obtained by us is characterized by the degree of consistency of the answers of the group of experts in assessing the factors under study. A coefficient of variation was used, which can be up to $35 \%$ to determine the degree of consistency of the respondents' answers. The level of consistency of responses in our studies ranges from $14 \%$ to $33 \%$ [20].

The level of consistency of the experts' answers was also determined by the concordance coefficient. In our case, the concordance coefficient is equal to 0.83 ; indicating a high level of consensus of experts.

In the process, we conducted a study of the features of the assortment policy of PS, which are part of the PC of different sizes, which included the following stages. The analysis of differences in single-input tables of frequency of repetition of qualitative features and connections in two-input conjugation tables was carried out using Pearson's criteria $\chi^{2}$ and maximum likelihood criteria $\chi^{2}\left(\mathrm{M}-\mathrm{L} \chi^{2}\right)$ to identify features and factors of assortment policy that are significantly related to PC size.

Using the non-parametric analysis of variance of Kraskal - Wallis, the significance of the influence of PC size on the scores of the efficiency of the business process of assortment formation, as well as the width of the range of drugs and MP and the intensity of its renewal.

We used the Manfer-Whitney criterion with the Bonferroni amendment for pairwise comparisons of PC clusters in terms of width, update intensity, and range formation efficiency.

The strength of the PC size connection was evaluated with the scores of the efficiency of assortment formation using correlation analysis, with the assortment width and with the intensity of its renewal. For this purpose, we calculated the rank correlation coefficient Kendall.

Z-criterion for comparing the frequency of use (in percent, \%) of different factors of inclusion of drugs and MPs in the range of PC and exclusion of drugs / MPs from the range of PCs of different sizes, the calculation results of which were used to divide the factors into groups by frequency of use.

Statistica, Microsoft Word, Excel were used in the process.

\section{Research results}

The first step of the algorithm is to analyze the relationship between PC size (small, medium, large and mega-) and the approaches used to form and analyze the formation of PR (centralized, decentralized and mixed). Indicators for this were selected based on the results of an expert survey.

There is a statistically significant relationship between PC size and the approaches used to form and analyze PR (M-L $\chi^{2}=13.96, p=7.42 \cdot 10^{-3}<0.05$ ) (Fig. 2, 3).

Further analysis showed that the cluster of small PCs use different approaches to the formation of PR with the same frequency $\left(\chi^{2}=1.39, \mathrm{p}=0.49>0.05\right)$.

\begin{tabular}{|c|c|c|c|c|}
\hline \multirow[b]{2}{*}{ chain size } & \multicolumn{4}{|c|}{$\begin{array}{c}\text { 2-Way Summary Table: Observed Frequencies } \\
\text { (QUESTIONNAIRE } 2 \text { Excel) } \\
\text { Marked cells have counts }>10\end{array}$} \\
\hline & $\begin{array}{l}\text { (18) the } \\
\text { approach to the } \\
\text { analysis and } \\
\text { formation of } \\
\text { the range is } \\
\text { decentralized }\end{array}$ & $\begin{array}{l}\text { (18) the } \\
\text { approach to the } \\
\text { analysis and } \\
\text { formation of } \\
\text { the range is } \\
\text { mixed }\end{array}$ & $\begin{array}{l}\text { (18) the } \\
\text { approach to the } \\
\text { analysis and } \\
\text { formation of } \\
\text { the range is } \\
\text { centralized }\end{array}$ & $\begin{array}{c}\text { Row } \\
\text { Totals }\end{array}$ \\
\hline small & 28 & 28 & 36 & 92 \\
\hline medium & 36 & 71 & 84 & 191 \\
\hline large/mega & 16 & 47 & 75 & 138 \\
\hline Totals & 80 & 146 & 195 & 421 \\
\hline
\end{tabular}

Fig. 2 Analysis of the relationship between PC size and the approaches used to analyze and generate PR

\begin{tabular}{|l|c|c|c}
\hline \multirow{2}{*}{ Statistic } & \multicolumn{3}{|c}{$\begin{array}{c}\text { Statistics: chain size (3) * (18) approach to the analysis and } \\
\text { formation of the range (3) }\end{array}$} \\
\cline { 2 - 4 } & Chi-square & $\mathrm{df}$ & $\mathrm{p}$ \\
\hline $\begin{array}{l}\text { Pearson } \\
\text { Chi-square }\end{array}$ & 14.32432 & $\mathrm{df}=4$ & $\mathrm{p}=0.00633$ \\
\hline $\begin{array}{l}\text { M-L Chi- } \\
\text { square }\end{array}$ & 13.96139 & $\mathrm{df}=4$ & $\mathrm{p}=0.00742$ \\
\hline $\begin{array}{l}\text { Kendall's tau } \\
\mathrm{b} \& \mathrm{c}\end{array}$ & $\mathrm{b}=0.1409774$ & $\mathrm{c}=0.1340717$ & \\
\hline Gamma & 0.2204626 & & \\
\hline
\end{tabular}

Fig. 3 The value of the criteria $\chi^{2}$ Pearson and $\chi^{2}$ maximum likelihood (M-L $\left.\chi^{2}\right)$

Medium-sized PCs are more likely to use a centralized or mixed approach to PR analysis and generation than a decentralized approach $\left(\chi^{2}=19.36\right.$, $\left.\mathrm{p}=6.25 \cdot 10^{-5}<0.05\right)$. For large and mega-PCs, a centralized approach to PR formation is more common, mixed is less commonly used, and very rarely large and mega-PCs use a decentralized approach to PR analysis and formation $\left(\chi^{2}=37.87, p=5.98 \cdot 10^{-9}<0.05\right)$.

The results of calculating the significance of differences between the frequency of use of different approaches to the formation of PR in PC clusters of different sizes by Pearson's criterion $\chi^{2}$ are given in Table 1 . Thus, the results of the study conclude that most part of large and mega-PCs mainly use a centralized approach to the analysis and formation of PR in their PS, medium centralized or mixed, and for small PCs there is no single preferred approach to the formation assortment policy.

The next stage of the study was to analyze the presence of the procedure for the formation of PR in PS, which are part of the PC of different sizes. In the course of work it was established that in each of three clusters the absolute minority of heads recognized absence of procedure of formation of assortment in the PS (for a cluster of large and mega-PCs: $\chi^{2}=36.04, p=1.49 \cdot 10^{-}$ ${ }^{8}<0.05$; for a cluster of medium PCs: $\chi^{2}=26.68$, $p=1.61 \cdot 10-6<0.05$; for a cluster of small PCs: $\chi^{2}=16.72$, $\mathrm{p}=2.34 \cdot 10-4<0.05)$. 
Table 1

Analysis of the frequency of use of different approaches to the formation of PR in PCs belonging to different clusters

\begin{tabular}{|c|c|c|c|c|c|c|c|c|c|c|}
\hline \multirow{3}{*}{\multicolumn{2}{|c|}{$\mathbf{N}$}} & \multicolumn{9}{|c|}{ PC size } \\
\hline & & \multicolumn{3}{|c|}{ Small } & \multicolumn{3}{|c|}{ Medium } & \multicolumn{3}{|c|}{ Large or mega- } \\
\hline & & 36 & 28 & 28 & 84 & 71 & 36 & 75 & 47 & 16 \\
\hline$\chi^{2}$ & $p$ & centralized & mixed & decentralized & centralized & mixed & decentralized & centralized & mixed & decentralized \\
\hline \multirow{3}{*}{ 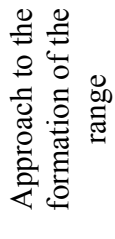 } & $\begin{array}{l}\text { tral- } \\
\text { ized } \\
\end{array}$ & & 0.3816 & 0.3816 & & 0.3351 & $* 1.78 \times 10^{-5}$ & & $* 0.0145$ & $\$ 1.201 \times 10^{-9}$ \\
\hline & mixed & 0.7656 & & 0.8937 & 0.9290 & & $\$ 0.0010$ & 5.975 & $><$ & $* 1.57 \times 10^{-4}$ \\
\hline & $\begin{array}{c}\text { decen- } \\
\text { tral- } \\
\text { ized }\end{array}$ & 0.7656 & 0.0179 & & 18.408 & 10.804 & & 36.967 & 14.286 & \\
\hline \multicolumn{2}{|c|}{$\begin{array}{l}\text { A number of } \\
\text { advantages: }\end{array}$} & \multicolumn{3}{|c|}{ Centr. $=$ Decen.$=$ Mix. } & \multicolumn{3}{|c|}{ Centr. $=$ Mix. $>$ Decen.} & \multicolumn{3}{|c|}{ Centr. $>$ Mix. $>$ Decen. } \\
\hline
\end{tabular}

Note: $N$ - frequency of application of the used approach (number of PS adhering to this approach to the formation of the range);

* - the weight of the differences between the frequencies

However, as a result of the analysis it was found that there is a certain number of PS, where the procedure for forming PR is officially approved. But most pharmacies use the personal experience of the pharmacy manager and the recommendations of consulting agencies instead of the approved procedure. Such pharmacies are represented in each cluster in equal proportions (for a cluster of large and mega-PCs: $\chi^{2}=0.29, \mathrm{p}=0.59>0.05$; for a cluster of medium PCs: $\chi^{2}=3.35, \mathrm{p}=0.06 .73 \cdot 10-4>0.05$; for a cluster of small PCs: $\chi^{2}=3.33, p=0.0682>0.05$ ) (Fig. 4 and Fig. 5). Thus, regardless of the size of the PC (M-L $\chi^{2}=9.20$, $\mathrm{p}=0.06>0.05)$ in most PS the formation of the range is based on either the personal experience of the head and the recommendations of consulting agencies, or according to the approved PR headquarters procedure.

\begin{tabular}{|c|c|c|c|c|}
\hline \multirow[b]{2}{*}{ chain size } & \multicolumn{4}{|c|}{$\begin{array}{c}\text { 2-Way Summary Table: Observed Frequencies } \\
\text { (QUESTIONNAIRE } 2 \text { Excel) } \\
\text { Marked cells have counts }>10\end{array}$} \\
\hline & $\begin{array}{l}\text { (20) } \\
\text { availability of } \\
\text { the standard of } \\
\text { assortment } \\
\text { formation } \\
\text { No }\end{array}$ & $\begin{array}{l}\text { (20) availability } \\
\text { of the standard of } \\
\text { assortment } \\
\text { formation } \\
\text { experience \& } \\
\text { recommendations }\end{array}$ & $\begin{array}{l}(20) \\
\text { availability of } \\
\text { the standard of } \\
\text { assortment } \\
\text { formation } \\
\text { Yes }\end{array}$ & $\begin{array}{c}\text { Row } \\
\text { Totals }\end{array}$ \\
\hline small & 15 & 47 & 30 & 92 \\
\hline medium & 33 & 91 & 67 & 191 \\
\hline large/mega & 13 & 59 & 66 & 138 \\
\hline Totals & 61 & 197 & 163 & 421 \\
\hline
\end{tabular}

Fig. 4. The results of statistical processing of the analysis of the presence of the procedure of forming PR in a PC of different sizes

\begin{tabular}{|l|c|c|c|}
\hline \multirow{2}{*}{ Statistic } & \multicolumn{3}{|c|}{$\begin{array}{c}\text { Statistics: chain size (3)*(20) availability of the standard of } \\
\text { assortment formation (3) }\end{array}$} \\
\cline { 2 - 4 } & Chi-square & $\mathrm{df}$ & $\mathrm{p}$ \\
\hline $\begin{array}{l}\text { Pearson } \\
\text { Chi-square }\end{array}$ & 9.051626 & $\mathrm{df}=4$ & $\mathrm{p}=0.05982$ \\
\hline $\begin{array}{l}\text { M-L Chi- } \\
\text { square }\end{array}$ & 9.200327 & $\mathrm{df}=4$ & $\mathrm{p}=0.05628$ \\
\hline $\begin{array}{l}\text { Kendall's tau } \\
\text { b \& c }\end{array}$ & $\mathrm{b}=0.1188786$ & $\mathrm{c}=0.1113399$ & \\
\hline Gamma & 0.1896989 & & \\
\hline
\end{tabular}

Fig. 5. The value of the $\chi^{2}$ Pearson criteria and $\chi^{2}$ maximum likelihood (M-L $\chi^{2}$ )
The third stage of the algorithm is to study the impact of PC size on the efficiency of the business process - the formation of PR, as well as on the width of the range and the intensity of its update.

As a result of an expert survey, the efficiency of the business process - the formation of PR were evaluated PS, which are part of the PC of different sizes, at the same level (Kruskal-Wallis H $(2.42)=3.02, p=0.22>0.05$ ). For small and medium-sized PCs, the evaluation of the effectiveness of $\mathrm{PR}$ formation averaged 4 points on a five-point scale, for large and mega-PC - 5 points. In all clusters, the assessment of the effectiveness of PR formation ranged from 3 to 5 points (Fig. 6). The calculated correlation between PC size and PR generation efficiency is almost zero $(\tau=0.07$, $\mathrm{p}=0.04$ ), which indicates that there is no dependence of the efficiency of this business process on the PC size.

It is established that small, medium and large PCs differ significantly in PR (Kruskal-Wallis $\mathrm{H}$ $\left.(2,42)=27.59, \mathrm{p}=0.00 \cdot 10^{-2}<0.05\right)$ (Fig. 7), although the existing correlation between PC size and PR width is quite weak $\left(\tau=0.22, p=6.89 \cdot 10^{-12}\right)$. For PR pharmacies belonging to small PCs, the presence of an average of 3 thousand items of drugs and MP is typical, but for half of them there may be a smaller number of assortment items (up to 2.5-3 thousand items).

Half of the PS, which are part of the mediumsized PC, have in their range of 4-5 thousand assortment items. The range of medium PCs is significantly wider than small PCs (Mann-Whitney $\mathrm{U}=7199.5, \mathrm{Z}=-2.55, \mathrm{p}=1.07 \cdot 10^{-2}<1.67 \cdot 10^{-2}$ ). For PS, which belong to the large and mega-PC, on average, the presence in the range of up to 8.5 thousand items of drugs and MP, and in $50 \%$ of such institutions, the width of PR varies in the range from 5 thousand to 8 thousand items. Large PCs in the width of the range significantly outperform the medium (Mann-Whitney $\mathrm{U}=10043, \mathrm{Z}=3.79, \mathrm{p}=1.52 \cdot 10^{-4}<1.67 \cdot 10^{-2}$ ), and small ones (Mann-Whitney $U=4097.5, Z=4.70, p=0.3 \cdot 10^{-5}<0.02$ ).

The relationship between the number of new names of drugs that appear on average in the PS range for one month for PCs of different sizes was also analyzed. It was found that the number of new drugs 
introduced in PR PS is statistically significant does not depend on the size of the PC, which is presented in Fig. 8 (Kruskal-Wallis H (2.42) $=5.62, \quad \mathrm{p}=0.06>0.05)$. The correlation between the size of the PC and the number of new drugs that appear on average in the range of its facilities during the month is close to zero $\left(\tau=0.09, p=2.34 \cdot 10^{-3}\right)$.
At the next stage of the work it was established [20] that the relationship between the intensity of updating the range of MP and the size of the $\mathrm{PC}$ is statistically significant (Kruskal-Wallis H $(2,421)=9.79$, $\mathrm{p}=0.74 \cdot 10^{-2}<0.05$, Fig. 9).

Box Plot of (12) efficiency of assortment formation grouped by chain size

QUESTIONNAIRE 2 Excel $164 \mathrm{v} * 421 \mathrm{c}$

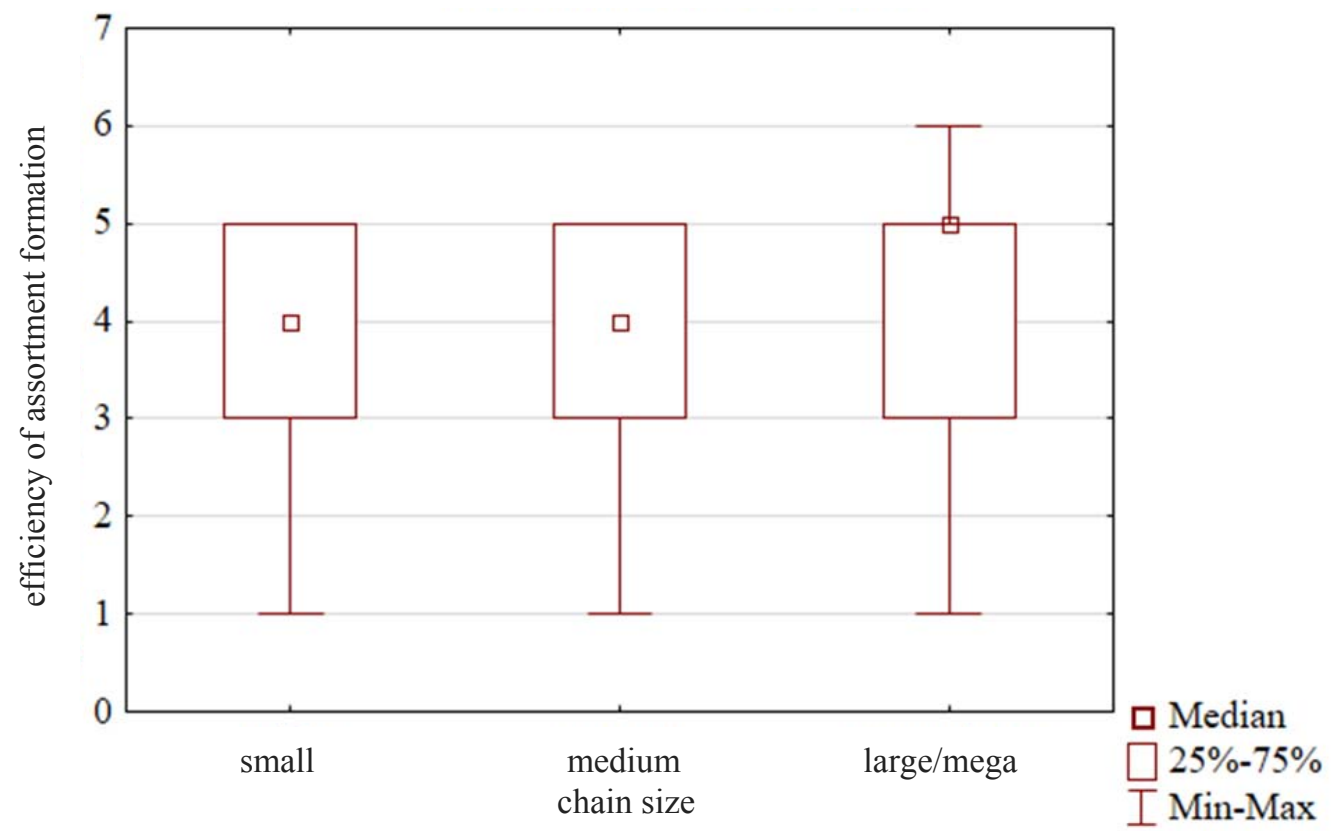

Fig. 6. Graph of the scope of assessments of the effectiveness of the business process of PR formation depending on the size of the PC

Box Plot of (13) number of assortment items grouped by chain size QUESTIONNAIRE 2 Excel 164v*421c

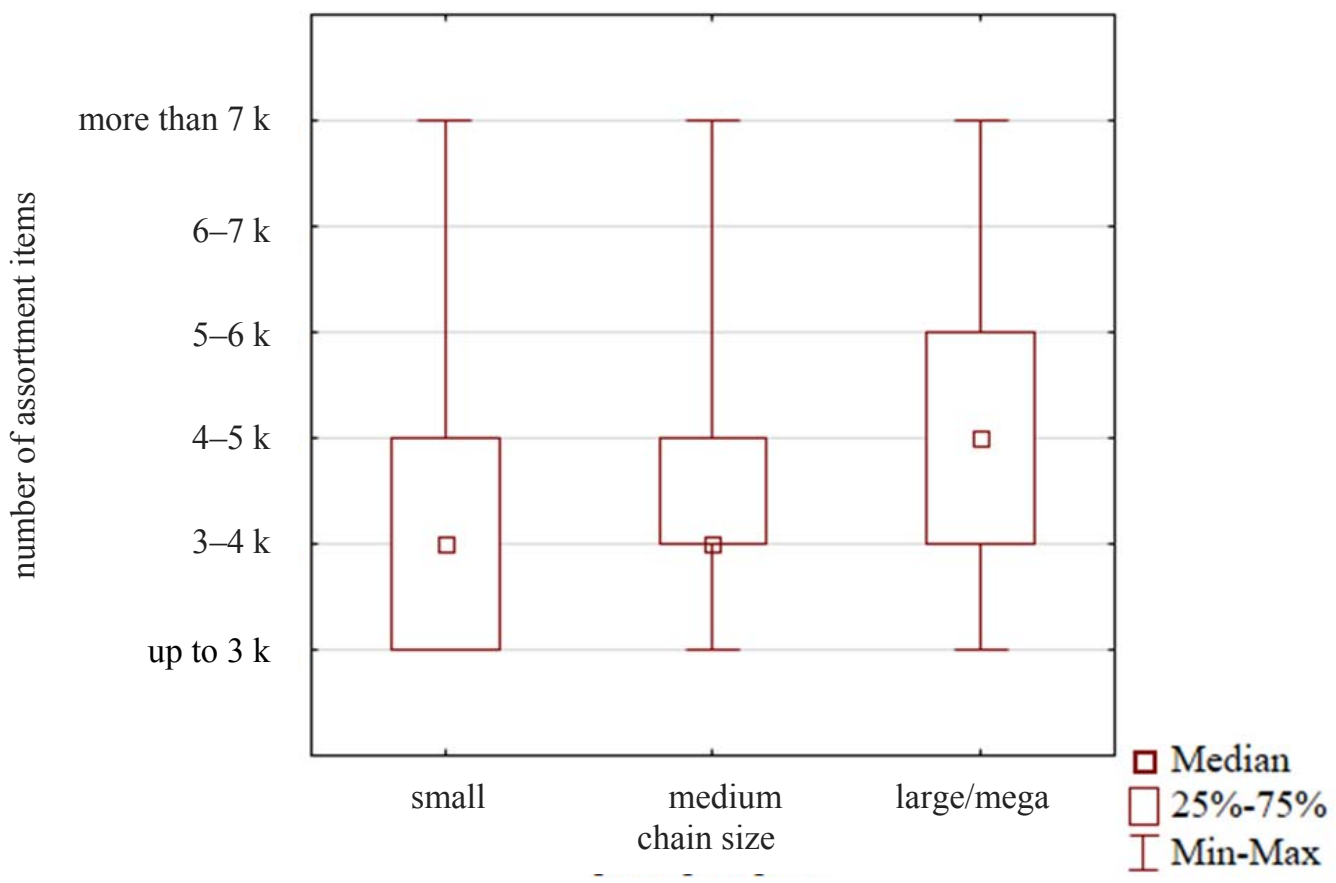

Fig. 7. Graph of the scope of the number of names of drugs and MPs present on average in the range of PS in small, medium, large and mega-PC 
Box Plot of (14) number of new drugs per month grouped by chain size QUESTIONNAIRE 2 Excel $164 v^{*} 421 \mathrm{c}$

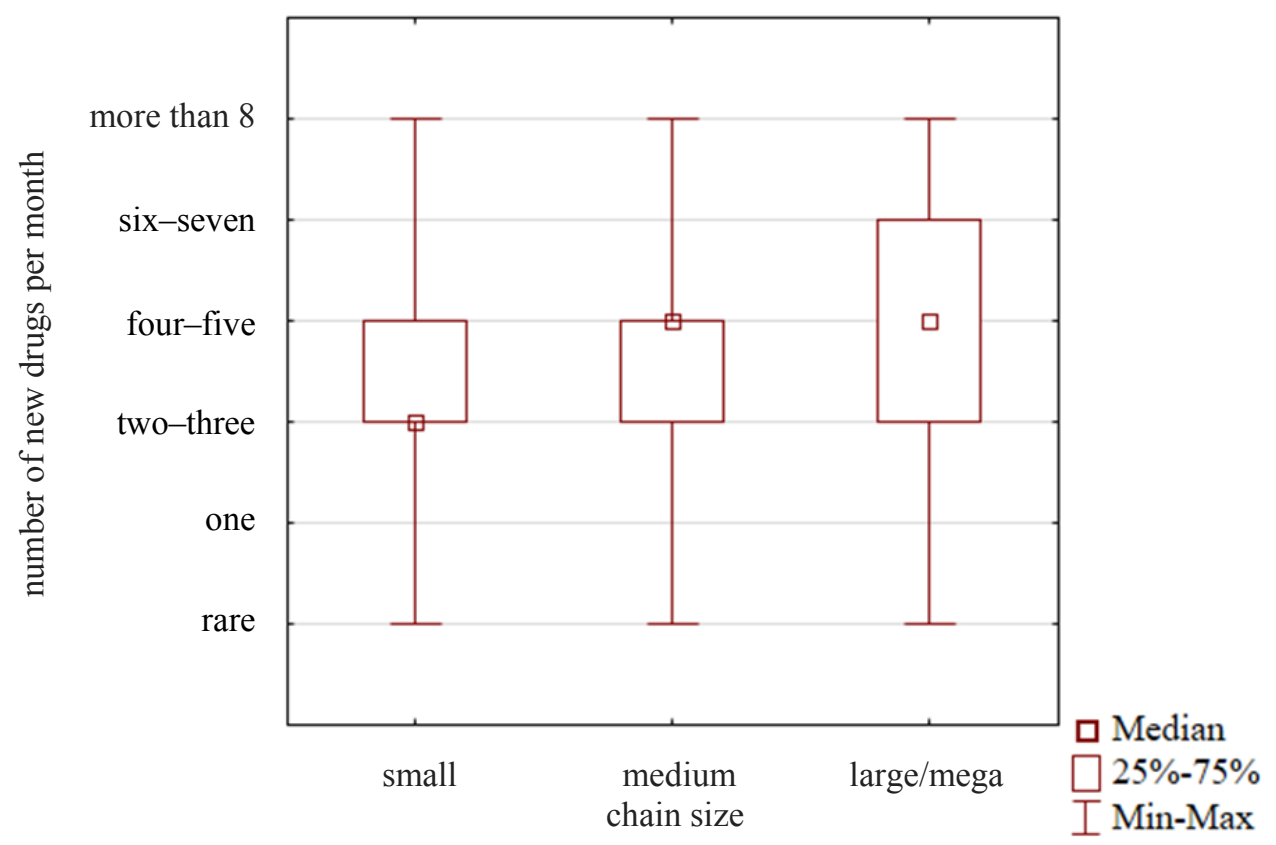

Fig. 8. Graph of the scope of the number of new drugs that appear in the PS range on average during the month, depending on the size of the PC

Box Plot of (15) number of new MP per month grouped by chain size QUESTIONNAIRE 2 Excel 164v*421c

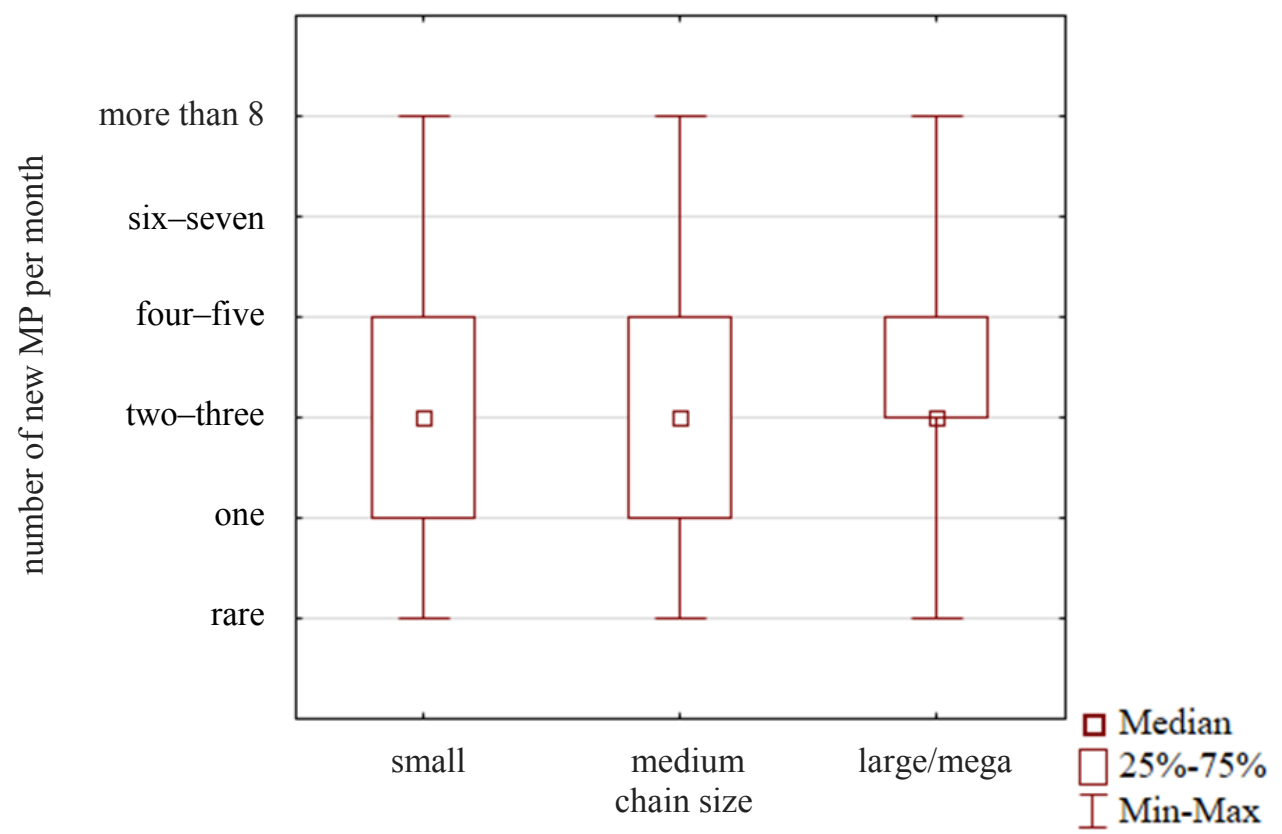

Fig. 9. Graph of the number of new MP names that appear in the PS range on average during the month, depending on the size of the PC

Moreover, it was found that in pharmacies belonging to medium and small PCs, this figure is the same (MannWhitney $\mathrm{U}=8524.5, \mathrm{Z}=0.42, \mathrm{p}=0.67>0.02$ ) and in $50 \%$ of cases varies from 1 to 5 new positions per month. For large PCs and mega-PCs, it is significantly higher (MannWhitney $\left.U=10970, Z=2.68, p=0.73 \cdot 10^{-2}<0.01667\right)$ and in half of the cases exceeds 3 assortment items during the month.

Next, the Z-criterion was used to compare the severity of the influence of various factors on the decision to include drugs and MP in PR and their exclusion from the range of pharmacies in small, medium, large and mega-PC. 
Calculations of all applied statistical criteria were performed with a $95 \%$ confidence level.

The analysis of the factors taken into account by PS at inclusion of drugs and MP to PR was also carried out in work.

It was found that only one of them is statistically significantly related to PC size - the presence of drugs in treatment protocols $\left(\mathrm{M}-\mathrm{L} \chi^{2}=11.12, \mathrm{p}=3.85 \cdot 10^{-3}<0.05\right)$. Moreover, institutions that are part of the PC of medium size, take into account this factor in the formation of PR at least $-18.85 \%$ of cases compared to $36.96 \%$ of pharmacies in small $\mathrm{PC}\left(\mathrm{Z}=3.14, \mathrm{p}=8.55 \cdot 10^{-4}<0.05\right)$, and with $28.26 \%$ of pharmacies from large and mega- PC $(\mathrm{Z}=1.98, \mathrm{p}=0.02<0.05)$. The frequency of use of this factor in the formation of PR between large and small PCs does not differ significantly $\left(\mathrm{Z}=1.38, \mathrm{p}=8.46 \cdot 10^{-2}>0.05\right)$.

\section{Discussion of research results}

The analysis of the assortment policy of PS, which are part of three clusters of different PC sizes, allowed to establish both the general principles of its implementation and the features characteristic of the assortment policy of PCs of different sizes (Fig. 10). It is established that with the increase of PC size the tendency to use a centralized approach to analysis and formation of PR in PC increases, when the list of assortment items is completely created and approved in the head office of the network.

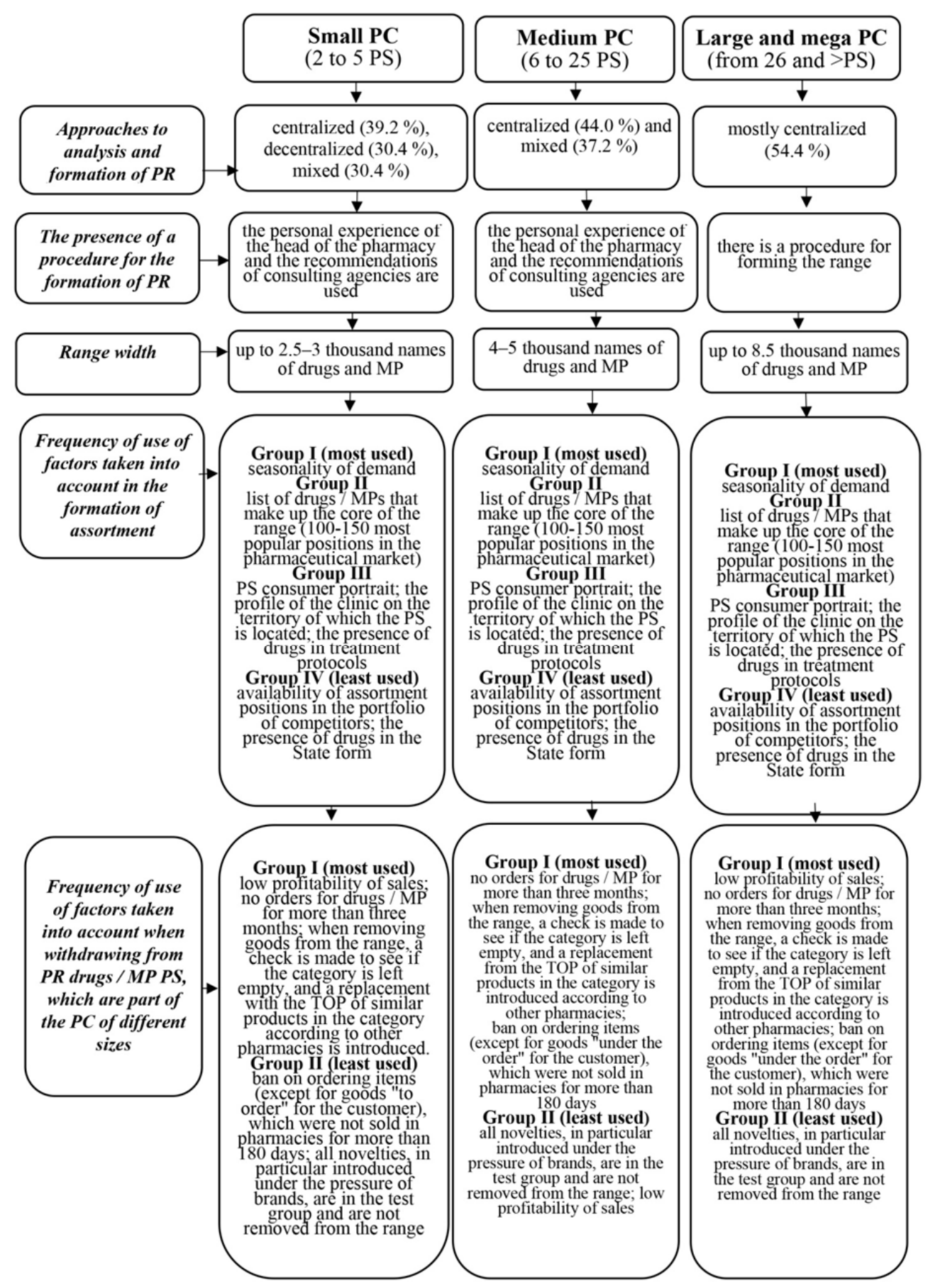

Fig. 10. Systematization of the used approaches to PR management in PC of the different size (on quantity of SU as a part of PC) 
This approach is typical for the majority of PSs that are part of large and mega-PCs $(54.4 \%)$.

In PS, which belong to the medium-sized PC, approximately equally often used centralized (44.0\%) and mixed approaches $(37.2 \%)$ to the analysis and formation of PR. In the latter case, the head office is responsible for forming only the main range of the pharmacy, and the rest of the items are added at the level of a specific PS. As for PS in small networks, among them the shares of pharmacies with different approaches used to the formation and analysis of PR (centralized, decentralized, or mixed) are presented in approximately the same proportions $(39.2 \%, 30.4 \%$ and $30.4 \%$ in accordance). Given that the effectiveness of the business process of PR in PS all three clusters was evaluated at the same fairly high level (4-5 points on a five-point scale), we can conclude that it is appropriate to use different approaches to the analysis and formation of PR in PC of different sizes.

Thus, small chains tend to give more freedom to individual PS and in a third of cases use a decentralized approach to the formation of PR, and large and mega$\mathrm{PCs}$ tend to greater centralization.

The situation with the presence of the procedure of PR formation in all studied pharmacies, as a rule, does not depend on the size of the PC, which they are part of. There is a fairly small percentage of PCs where the standard of assortment formation is absent.

At the same time, in the vast majority of PCs in the same proportions are institutions where the procedure for forming the range is developed and implemented, and where instead the personal experience of the head of the pharmacy and the recommendations of consulting agencies are used.

This indicates the relevance of such an area of improvement of the PC as the development and implementation of standards of basic business processes, among which one of the most important is the process of forming PR institutions that are part of the network.

The significance of the relationship between the latitude of PR PS and the size of the chain to which it belongs is statistically confirmed. Thus, large and megaPCs support a range in their institutions, which on average includes up to 8.5 thousand items of drugs and MP, medium - 4-5 thousand assortment items, and in half of small PC establishments the range can include from 2.5 to 3 thousand names of drugs and MP. It was found that regardless of the size of the PC when including drugs / MP in the range of PS most often take into account the factor of seasonality of demand and taking into account the core range, i.e. the list of 100-150 most popular positions in the pharmaceutical market.
When withdrawing drugs or MPs from the range of PS from all three clusters are often guided by indicators of low profitability of sales and lack of orders for goods for more than three months.

The advantages of the results of the study include:

- analysis of the assortment policy of different PCs sized was done;

- approaches to the analysis and formation of PR in small, medium and large PCs are analyzed;

- the presence of the procedure for forming the product range in PS, which are part of the $\mathrm{PC}$ of different sizes, was analyzed;

- the influence of the size of the PC on the efficiency of the business process of forming the product range, as well as on the width and intensity of the update;

- analyzed the factors that should be taken into account when including and removing drugs and MP to the product range of PCs of different sizes.

We analyzed the features of product range management in PCs of different sizes. It should be noted that other authors have conducted research on the formation of the range for individual pharmacies. Thus, in [3] the use of the economic component in the formation of the assortment policy of pharmacies.

The limitations of the study include the possibility of applying the results to domestic PCs.

Prospects for further research include the need for continuous study of the influence of environmental factors on the formation of PR PC. In the future, it will be advisable to formalize the relationship between PC size and assortment policy by building appropriate economic and mathematical models that will allow you to assess in advance the results of adjusting the assortment policy in PCs of different sizes.

\section{Conclusions}

Thus, the analysis of the assortment policy of different sized PCs showed that in most of the studied institutions it is quite reasonable. The obtained results allow us to conclude that the effectiveness of analysis and formation of PR is achieved through the use of different approaches to the centralization of this business process depending on the size of the PC. There are some peculiarities in the use of criteria for inclusion or exclusion of drugs and MPs with PR PS, due to the size of the PC in which they operate, which indicates the presence of a differentiated approach to the implementation of assortment policy in small, medium and large PCs.

\section{Conflict of interests}

The authors declare that they have no conflicts of interest.

\section{References}

1. Posilkina, O. V., Mala, Zh. V., Bondarieva, I. V. (2019). Development of methodical approaches to the assortment management of pharmacy networks by principles of categorycal management. ScienceRise: Pharmaceutical Science, 1 (17), 4-11. doi: http://doi.org/10.15587/2519-4852.2019.157601

2. Mejia, V., Aurier, P., Huaman, R. R. (2020). Disentangling the respective impacts of assortment size and alignability on perceived assortment variety. Journal of Retailing and Consumer Services, 59, 102386. doi: http://doi.org/10.1016/j.jretconser.2020.102386

3. Puzak, N. O., Aleksieieva, T. I., Puzak, O. A. (2014). Use of economic component in assortment policy formation of pharmaceutical companies. Management, economics and quality assurance in pharmacy, 1 (33), 23-27.

4. Pizzi, G., Scarpi, D. (2016). The effect of shelf layout on satisfaction and perceived assortment size: An empirical assessment. Journal of Retailing and Consumer Services, 28, 67-77. doi: http://doi.org/10.1016/j.jretconser.2015.08.012 
5. Kovalevska, I. V., Ruban, O. A., Yevtushenko, O. M. (2019). Researches of the assortment of drugs for the treatment of diabetes II type on the pharmaceutical market of Ukraine. Farmatsevtychnyi zhurnal, 2, 13-23. doi: http://doi.org/10.32352/0367-3057.2.19.02

6. Lebedynets, V. O., Kazakova, I. S. (2020). The analysis and determination of prospects for the development of the market of medicinal cosmetic products in Ukraine. Social Pharmacy in Health Care, 6 (2), 44-60.

7. Nemchenko, A. S., Mishchenko, V. I., Nemchenko, O. A. (2019). Analysis of medicines assortment and parapharmaceuticals based on polynesaturated fatty acids in Ukraine. Management, economy and quality assurance in pharmacy, 2 (58), 38-45. doi: http://doi.org/10.24959/uekj.19.13

8. Gorilyk, D. V., Gorilyk, A. V., Popovych, V. P., Gromovyk, B. P. (2011). Tool for automated integrated ABC / FMR / (XYZ) / VED-analysis. Clinical pharmacy, pharmacotherapy and medical standardization, 3-4, 175-178.

9. Bernstein, F., Kök, A. G., Xie, L. (2015). Dynamic assortment customization with limited inventories. Manufacturing \& Service Operations Management, 17 (4), 538-553. doi: http://doi.org/10.1287/msom.2015.0544

10. Bertrandie, L., Zielke, S. (2017). The effects of multi-channel assortment integration on customer confusion. The International Review of Retail, Distribution and Consumer Research, 27 (5), 437-449. doi: http://doi.org/10.1080/09593969.2017.1383292

11. Emrich, O., Paul, M., Rudolph, T. (2015). Shopping benefits of multichannel assortment integration and the moderating role of retailer type. Journal of Retailing, 91 (2), 326-342. doi: http://doi.org/10.1016/j.jretai.2014.12.003

12. Kahn, B. E. (2017). Using visual design to improve customer perceptions of online assortments. Journal of Retailing, 93 (1), 29-42. doi: http://doi.org/10.1016/j.jretai.2016.11.004

13. Andryushayev, O. V., Ruban, O. A., Masliy, Yu. S., Iakovlieva, L. V. (2020). The current state and the development prospects of the Ukrainian market of antihistamines. Social Pharmacy in Health Care, 6 (2), 69-80. doi: http://doi.org/10.24959/sphhcj.20.180

14. Kotvitska, A. A., Cherkashyna, A. V., Volkova, A. V., Kubareva, I. V. (2018). Analysis of the current state and the dynamics of lipid-lowering drugs in the pharmaceutical market of Ukraine. Asian Journal Pharmaceutical Clinical Research, 11 (6), 358-362. doi: http://doi.org/10.22159/ajpcr.2018.v11i6.22702

15. Ranyard, J. C., Fildes, R., Hu, T. I. (2015). Reassessing the scope of OR practice: the influences of problem structuring methods and the analytics movement. European Journal of Operational Research, 245 (1), 1-13. doi: http://doi.org/10.1016/j.ejor.2015.01.058

16. Rooderkerk, R. P., Van Heerde, H. J., Bijmolt, T. H. (2013). Optimizing retail assortments. Marketing Science, 32 (5), 699-715. doi: http://doi.org/10.1287/mksc.2013.0800

17. Saghiri, S., Wilding, R., Mena, C., Bourlakis, M. (2017). Toward a three-dimensional framework for omni-channel. Journal of Business Research, 77, 53-67. doi: http://doi.org/10.1016/j.jbusres.2017.03.025

18. Sinha, A., Sahgal, A., Mathur, S. K. (2013). Practice prize paper-category optimizer: A dynamic-assortment, new-productintroduction, mix-optimization, and demand-planning system. Marketing Science, 32 (2), 221-228. doi: http://doi.org/10.1287/ mksc.1120.0746

19. Zvit Antymonopolnoho komitetu Ukrainy za rezultatamy doslidzhennia farmatsevtychnykh rynkiv (2016). Kyiv, 240. Available at: https://www.apteka.ua/article/392373 Last accessed: 22.04.2021

20. Kendall, M., Stiuart, A. (1973). Statisticheskie vyvody i sviati. Vol. 2. Moscow: Nauka, 899.

Received date 18.02.2021

Accepted date 20.04.2021

Published date 30.04.2021

Olga Posilkina, Doctor of Pharmaceutical Sciences, Professor, PhD, Department of Management, Economics and Quality Assurance in Pharmacy, National University of Pharmacy, Pushkinska str., 53, Kharkiv, Ukraine, 61002 E-mail: o.posilkina@gmail.com

Iryna Bondarieva, $\mathrm{PhD}$, Associate Professor, Department of Pharmaceutical Management and Marketing, National University of Pharmacy, Pushkinska str., 53, Kharkiv, Ukraine, 61002

E-mail: fmm@nuph.edu.ua

Volodymyr Malyi, Doctor of Pharmaceutical Sciences, Professor, Department of Pharmaceutical Management and Marketing, National University of Pharmacy, Pushkinska str., 53, Kharkiv, Ukraine, 61002

E-mail: fmm@nuph.edu.ua

Iryna Timanyuk, PhD, Associate Professor, Department of Pharmaceutical Management and Marketing, National University of Pharmacy, Pushkinska str., 53, Kharkiv, Ukraine, 61002

E-mail: fmm@nuph.edu.ua

Zhanna Mala, PhD, Department of Pharmaceutical Management and Marketing, National University of Pharmacy, Pushkinska str., 53, Kharkiv, Ukraine, 61002

E-mail: fmm@nuph.edu.ua 